\title{
An Analysis of the Perspective of Last Year Medical Students in Training Allocated to Manage COVID-19 Hospital Patients in Mexico
}

Gabriela Y.C. Moreno ( $D$ medic_gaby@live.com.mx)

Secretaría de Salud de Mexico: Secretaria de Salud de Mexico https://orcid.org/0000-0002-4506-8223

Miguel Jesús Torres Ruiz

Instituto Politécnico Nacional: Instituto Politecnico Nacional

Eleazar Lara Padilla

Instituto Politécnico Nacional Escuela Superior de Medicina: Instituto Politecnico Nacional Escuela Superior de Medicina

\section{Rosalba Garduño Zarazúa}

Secretaría de Salud de Mexico: Secretaria de Salud de Mexico

\section{Antonio Franco Vadillo}

Instituto Politécnico Nacional Escuela Superior de Medicina: Instituto Politecnico Nacional Escuela

Superior de Medicina

\section{José de Jesús Peralta Romero}

Instituto Mexicano del Seguro Social

José Bruno Mendoza Ramírez

Instituto Politécnico Nacional Escuela Superior de Medicina: Instituto Politecnico Nacional Escuela

Superior de Medicina

\section{Adrian Heald}

University of Manchester School of Medicine: The University of Manchester Faculty of Biology Medicine and Health

\section{Javier Mancilla Ramírez}

Secretaría de Salud de Mexico: Secretaria de Salud de Mexico

\section{Research Article}

Keywords: SARS-CoV-2, Covid-19, Pandemic, Health care workers, training, perception, feeling, information, Personal Protection Equipment

Posted Date: June 8th, 2022

DOl: https://doi.org/10.21203/rs.3.rs-522952/v2 
License: (a) (i) This work is licensed under a Creative Commons Attribution 4.0 International License. Read Full License 


\section{Abstract}

\section{Background}

In order to address the COVID-19 pandemic, health systems have used all their resources, including health care workers in training. Knowing the insights of these workers is of the utmost importance to generate adequate educative/political /administrative strategies.

\section{Methods}

An anonymous cross-sectional online survey was made by the General Directorate of Quality and Health Education in Mexico, in a convenience sample of 6,020 participants who belong to personnel in training for the health area, which included practitioners and professional technologists, undergraduate doctors, nursing, and residents in several specialties.

\section{Results}

Different positive and negative feelings were identified by the health workers who participated in facing this health emergency; emphasizing elements such as the need for Personal Protection Equipment (PPE) that, when deficient or lacking, generate concerns that raise questions about the medical/epidemiological attention to the pandemic.

Based on an analysis of feelings, 8 main feelings were identified, which by frequency of appearing were: distrust(24.83\%), fear(21.97\%), sadness(12.45\%), anticipation(11.65\%), anger(10.71\%), disgust(9.69\%), joy $(4.97 \%)$ and surprise(3.72\%) which influence health workers in training and their wrok performance day to day.

Concerning their positive and negative evaluation of their experience facing this health emergency, $13.83 \%$ of participants had a positive perception about participating in this kind of health emergency to support the country, $49.94 \%$ showed a negative evaluation, and $36.23 \%$ kept a neutral evaluation about their participation.

\section{Conclusions}

The health workers in training in Mexico gave a negative evaluation of the management of the health emergency. Distrust as a response to the absence of timely information from the education/health institutions, as well as concern about lack of personal protection equipment/inputs, are the main conflicts reported.

We must establish a credible globally relevant continuity plan for the education of health care personnel in training, facing emergencies and disasters, so that next time we are properly prepared.

\section{Background}


The first case of novel coronavirus SARS-CoV-2, also known as COVID-19 in Mexico was reported on February 28, 2020, and up to May 27, 2021, a total of 2,402,722 confirmed cases had been registered, 239,350 deaths, and 1,919,821 recoveries associated with the disease (1). The health systems of many countries, including Mexico, have taken on board the structural modifications that the pandemic has required, highlighting hospital conversion and extension, changes in work routines, the implementation and optimization of Personal Protection Equipment (PPE), and the strengthening of the disinfection techniques employed $(2,3)$.

COVID-19 has caused health institutions to improve the responsiveness in economic and human resources, mainly with the recruitment of health workers who possess the skills and capabilities that the pandemic merits (4). Nevertheless, this response often varies, since it has been reported that middle income countries lack enough personnel to face the pandemic. It has even required the participation of health workers in training from careers related to medicine to deal with the demand needed at this moment (5).

The pandemic, in turn, has caused in education and health institutions, the generation of strategies for the acceleration of education and training of new recruits for their integration into the growing demand of care for patients, who require general and also specialized consultations in COVID-19 in urban and rural areas (6).

In this sense, their participation has been key to managing the situation. However, the probability that a student in training or resident internship is exposed to COVID-19, has implied a change in their education, service responsibilities, continuous training and daily medical practice. (7).

In order to know how the health personnel in training from the different health areas are facing this health emergency and the needs that have arisen, an on-line anonymous survey was carried out. We asked about the academic and ethical conflicts that appeared in the response to this health emergency.

\section{Methods}

\section{Design of the Study, Population, and Environments}

This study consisted of a cross-sectional online survey, with a convenience sample of 6,020 people in training in the healthcare delivery area. Among them, workers who were in technical and professional training, undergraduate intern doctors, social service intern doctors and nurses, and resident doctors from the 32 states of the country were included.

\section{Data Collection}

The questionnaire was sent by email via the anonymous platform and asked respondents to complete the questions to the personnel in training registered in the platform of the General Directorate of Quality and Health Education (Dirección General de Calidad y Educación en Salud in Spanish). It was available from June 25 until October 25, 2020. Participation was voluntary and only one answer per person was allowed. 
The project received institutional ethics approval from the Medical Education Ethics Committee of General Directorate of Quality and Health Education.

The survey was based on that made by the Washington University School of Medicine (6), composed of 3 open questions, in order to obtain the opinions and attitudes of the health personnel to the COVID-19 pandemic in Mexico:

- Describe the academic or ethical conflicts that you have experienced because of the COVID-19 pandemic.

- ¿What conflicts have you experienced in your practice as a health worker in training caused by the COVID-19 pandemic?

- ¿ls there anything else you would like to mention about your experience as a health worker in training while the COVID-19 pandemic?

\section{Statistical Analysis}

The data collected in the survey were analyzed applying diverse techniques of processing of natural language, with the implementation of algorithms in language R 4.0.2 for Windows. Subsequently, a data repository was built in CSV format to process the information statistically and with a qualitative approach, that is, syntactically to obtain an analysis of feelings.

Additionally, a word cloud was built applying data mining functions on the corpus generated by the answers to the open question to obtain tendencies, defining a maximum number of 80 words, with a minimum frequency of occurrence of 3 (Fig. 1). A transformation was performed to obtain a matrix of terms, where the number of rows $m$ is equal to the number of different words of the corpus, and the number of columns $n$ is equal to the number of documents (each document is an entry of the corpus that represent the total size of the sample). The sum of vectors of the surveys were determined and were transformed into a bidimensional array that confirmed the corpus, using the Pearson's Correlation Coefficient for the association of words. Afterward, hierarchical clustering was performed using the Ward method (8), in order to observe the partitions generated in a hierarchy based on the most frequent terms. For the analysis of feelings, we identified and classified the reactions, attitudes, the context, and the emotions of the participants based on the NRC Emotion Lexicon dictionary (9) to classify each word in the following feelings: positive, negative, anger, anticipation, disgust, fear, joy, sadness, surprise, and distrust.

\section{Results}

The survey was answered by the health area personnel in training a total of 6,020 times. $70.3 \%$ or respondents were women with an average age of 24 years. The interns and technicians in nursing were the people with the highest participation in the survey, with a percentage of $27.7 \%$ and $16.4 \%$, respectively, followed by resident doctors with $13.3 \%$ and social service intern doctors $12.7 \%$ (Table 1 ). 
Table 1

Health professionals surveyed by age and sex, and occurrence of conflicts

\begin{tabular}{|c|c|c|c|c|c|}
\hline Health workers & Total (\%) & Man & Woman & $\begin{array}{l}\text { Age } \\
(\mu)\end{array}$ & $\begin{array}{l}\text { Experienced } \\
\text { conflicts }\end{array}$ \\
\hline Undergraduate intern doctors & $92(1.5 \%)$ & $48.9 \%$ & $51.1 \%$ & 23.7 & $56.0 \%$ \\
\hline Social service intern doctors & $\begin{array}{l}767 \\
(12.7 \%)\end{array}$ & $43.4 \%$ & $56.6 \%$ & 25.1 & $79.4 \%$ \\
\hline Resident doctors & $\begin{array}{l}796 \\
(13.2 \%)\end{array}$ & $49.9 \%$ & $50.1 \%$ & 28.8 & $46.8 \%$ \\
\hline Nurse practitioners & $\begin{array}{l}1669 \\
(27.7 \%)\end{array}$ & $20.7 \%$ & $79.3 \%$ & 24.0 & $37.9 \%$ \\
\hline Nursing technicians & $\begin{array}{l}989 \\
(16.4 \%)\end{array}$ & $24.9 \%$ & $75.1 \%$ & 21.2 & $29.9 \%$ \\
\hline Technicians in radiology & $49(0.8 \%)$ & $53.1 \%$ & $46.9 \%$ & 23.0 & $40.0 \%$ \\
\hline Odontology practitioner & $\begin{array}{l}567 \\
(9.4 \%)\end{array}$ & $28.2 \%$ & $71.8 \%$ & 24.4 & $23.3 \%$ \\
\hline Resident odontologist & $12(0.2 \%)$ & $41.7 \%$ & $58.3 \%$ & 29.6 & $40.0 \%$ \\
\hline $\begin{array}{l}\text { Chemistry, Pharmacy and Biologist } \\
\text { practitioner, Chemist-biologist }\end{array}$ & $\begin{array}{l}113 \\
(1.9 \%)\end{array}$ & $38.1 \%$ & $61.9 \%$ & 23.5 & $22.9 \%$ \\
\hline \multicolumn{6}{|l|}{ parasitologist and Pharmacy } \\
\hline Clinical Laboratory technician & $\begin{array}{l}122 \\
(2.0 \%)\end{array}$ & $25.4 \%$ & $74.6 \%$ & 18.1 & $27.1 \%$ \\
\hline $\begin{array}{l}\text { Rehabilitation, physical, and occupational } \\
\text { therapy practitioners }\end{array}$ & $\begin{array}{l}247 \\
(4.1 \%)\end{array}$ & $20.2 \%$ & $79.8 \%$ & 23.5 & $23.9 \%$ \\
\hline Physical therapy and rehabilitation technician & $17(0.3 \%)$ & $47.1 \%$ & $52.9 \%$ & 24.0 & $28.6 \%$ \\
\hline Practitioners in nutrition & $\begin{array}{l}408 \\
(8.8 \%)\end{array}$ & $15.7 \%$ & $84.3 \%$ & 23.8 & $20.3 \%$ \\
\hline Nutrition and dietetics technician & $25(0.4 \%)$ & $8.0 \%$ & $92.0 \%$ & 23.7 & $8.7 \%$ \\
\hline Optometry technician & $9(0.1 \%)$ & $22.2 \%$ & $77.8 \%$ & 32.2 & $44.4 \%$ \\
\hline Psychology practitioners & $87(1.4 \%)$ & $23.0 \%$ & $77.0 \%$ & 24.1 & $11.0 \%$ \\
\hline Social work practitioners & $29(0.5 \%)$ & $17.2 \%$ & $82.8 \%$ & 25.1 & $28.6 \%$ \\
\hline Social work technician & $13(0.2 \%)$ & $7.7 \%$ & $92.3 \%$ & 19.4 & $10.0 \%$ \\
\hline Other professions* & $9(0.1 \%)$ & $33.3 \%$ & $66.7 \%$ & 23.1 & $0.0 \%$ \\
\hline Total & $\begin{array}{l}6020 \\
(100.0 \%)\end{array}$ & $29.7 \%$ & $70.3 \%$ & 24.2 & $39.5 \%$ \\
\hline
\end{tabular}


The presence of conflicts in their education and daily practice as the result of the pandemic was mentioned in $39.5 \%$ of responses. The social service intern doctors and undergraduate intern doctors were the health workers in training with the highest frequency of academic conflicts, with a percentage of $79.4 \%$ in the first group and $56.0 \%$ in the second group. Likewise, the residents and the nursing practitioners had a high percentage of conflicts with $46.8 \%$ and $37.9 \%$, respectively. The personnel in training from careers related to health education experienced conflicts in a slightly lower proportion than the medical and nursing sector, ranging from 20 to $30 \%$ (Table 1 ).

The percentage based on the total terms used in the answers to each open question was $98.3 \%$. From the 6,020 analyzed documents, 4,249 common terms were defined, obtaining 4,252 different words.

According to the syntactic analysis of the open questions and their frequency of distribution, the main concerns of the health workers in training were:

lack $(11.95 \%)$, patients $(8.26 \%)$, protection $(7.35 \%)$, personnel (7.28\%), social service intern doctors $(7.25 \%)$, covid (5.79\%), health (5.55\%), practitioners (5.17\%), material (4.64\%), and equipment (4.50\%) (Fig. 1).

In order to observe the semantic relationship between the terms with a higher frequency, a dendrogram was built composed of 6 clusters, where each cluster represents the direct association between the terms. Cluster 1 "patient", is related with the partitions "attention" and "risk". The second cluster is composed of terms that reflect the needs. The third and fourth clusters associate information given by institutions, where it is observable that the term "lack" has a strong semantic relationship. The fifth and sixth clusters describe actions presented due to the pandemic, such as "suspension of classes" and "service" (Fig. 2).

Based on an analysis of feelings, 8 main feelings were identified, which by frequency of appearing were: distrust (24.83\%), fear (21.97\%), sadness (12.45\%), anticipation (11.65\%), anger (10.71\%), disgust (9.69\%), joy $(4.97 \%)$ and surprise $(3.72 \%)$.

Concerning their positive and negative evaluation of participation in this health emergency, $13.83 \%$ of participants had a positive perception about participating in this kind of health emergency to support the country, $49.94 \%$ showed a negative evaluation, and $36.23 \%$ kept a neutral evaluation about their participation.

\section{Discussion}

Since the notification of the existence and quick spread of the novel coronavirus SARS-CoV-2 in Mexico, the organization and implementation of hospital conversion in the country's Health National System has been instrumental in facing this emergency, as well as maximizing the nation's attention and facing the pressures of COVID-19 cases (10-12).

For the health crisis, it was considered necessary to enlist the participation of health workers in their last years of education, assigning them to non-COVID-19 hospitals, in order to discharge their academic and 
social functions (13). In this context, the strategies implemented were essential to fulfilling the demand that emerged in this situation, as well as to enable the health workers to complete their education efficiently (14).

The deficit of information provided by the academic institutions and the health sector, together with the lack of timely and efficient training about COVID-19 have seemed to mediate insecure behaviors, affecting not only the effective prevention measures but also the effectiveness of measures to lower the rate of infected people (15). Importantly high scores in knowledge tests about COVID-19 were significantly associated with a lower probability of negative attitudes and potentially dangerous practices to face the COVID-19 epidemic (16).

The COVID-19 virus has had a worldwide impact directly on the physical and mental health of millions of people (17). The COVID-19 pandemic has caused a generalized climate of caution, uncertainty, and stress, due to a wide variety of causes, particularly among health professionals (18) as we describe here.

The most recognized reported factors in our survey are the concern about the lack of personal protection equipment, exhaustion, worries about not being able to provide competent care if the disease extends to new areas, concerns about the scientific and clinical information that changes quickly, lack of access to information and up-to-date communications, the absence of specific medications, the shortage of ventilators and beds in the intensive care unit to address the emerging of critically ill patients, and a significant change in their social and family life plus education / training (19).

Around the world, there have been studied different surveys to understand and observe the behavior of health workers while facing the COVID-19 pandemic. Most of the studies in Latin America concluded that the surveyed health personnel feel uncertainty, fear, and anguish, but also there emerged a feeling of responsibility and a wish to face COVID-19 (20). This accords with our findings as described.

Among these large-scale surveys to health personnel, there stand out concerns about lack of institutional resources and availability of personal protection equipment. There are concerns about government measures like the absence of strategies of containment for the health workers and clear and standardized institutional communication, together with disquiet about creation of the necessary conditions to face the pandemic, access to information, and lack of integration among the subsectors of the system (21). Added to this, there are negative or neutral valuations of their participation as health personnel in this health emergency.

This study shows evidence that the health workers in training, who have experienced conflicts in their professional practice because of the COVID-19 pandemic, agree that the personal protection equipment and inputs are not enough. Despite having been placed in lower-risk areas, the social service intern doctors were assigned to biologically dangerous tasks, not having the appropriate equipment. This reinforces the feelings of fear, anger, sadness, distrust, and repulsion, which causes interpersonal conflicts with their coworkers, generating negative perceptions of their professional development and the need for continuous education, as implemented in other countries (22). 
The role played by e-learning, especially the educational platforms is important in these situations. Nevertheless, there still is a significant gap in the facility of this kind of teaching to enable the development of abilities and skills that this kind of emergency requires.

Knowing the insights of the health personnel is important in order to be able to generate community awareness and to develop the necessary social discipline to face the COVID-19 epidemic. As in other places in the world, there is annoyance and physical, social, emotional, and mental exhaustion in the health workers, which impacts directly on their personal and professional development.

We suggest the following interventions in the light of the findings in this survey

1. An action plan and continuity plan for the education of the health care personnel in training, facing emergencies and disasters by the education authorities of medical units, in which there are established the instructions and functions that the health personnel in training must perform, as well as the necessary provisions that the recipient unit considers about the material, personal protection equipment, training, etc.

2. To develop these guidelines based on the experience of the COVID-19 pandemic.

3. Interventions like timely information through the use of information technology (IT), mentoring by qualified and experienced personnel and support in the self-education material by the Educational Institutions.

4. Protection of the safety of undergraduate intern doctors and practitioners, and the deployment of training actions during the confinement, as well as a controlled plan of reincorporation once the emergency is over.

5. The need for psychological and social attention to human resources in training. The offering of psychological support could be made through helplines and chats in the different health services of each state and through the "Capas" or Psychological Attention Centres.

\section{Conclusion}

This survey highlights the concerns and needs related to the perception of the absence of enough input / educational support and mentoring, to face the Coronavirus pandemic and its impact on the mental health of health care professionals in training.

This study shows the need for developing action strategies that allow adequate training, orientation and mentoring of mental wellbeing in this kind of event.

This is the first study in the world to assess the perception of health personnel in training from the different health areas directly related to the care of COVID-19 patients in clinical or administrative activities who face the pandemic. In the light of the results, we must establish a credible globally relevant continuity plan for the education of health care personnel in training, facing emergencies and disasters now and in the future.

\section{What We Know}


In order to address the COVID-19 pandemic, health systems have used all their resources including the health care workers in training.

Knowing the insights of these workers is of the utmost importance to generate adequate educative, political and administrative strategies.

\section{What We Have Learnt}

Distrust as a response to the absence of timely information from the education and health institutions, as well as concern about the lack of personal protection equipment and inputs, are the main conflicts reported.

We must establish a credible globally relevant continuity plan for the education of health care personnel in training, facing emergencies and disasters so that next time we are properly prepared

\section{List Of Abbreviations}

PPE. Personal Protection Equipment

\section{Declarations}

\section{Ethics approval and consent to participate}

Not applicable

\section{Consent for publication}

Not applicable.

\section{Availability of data and materials}

The datasets used and/or analysed during the current study are available from the corresponding author on reasonable request.

\section{Competing interests}

The authors declare that they have no competing interests.

\section{Funding}

None.

\section{Competing interests}

The authors declare that they have no competing interests.

\section{Author information}


Gabriela Yanet Cortés Moreno ${ }^{1,5}$; Miguel Jesús Torres Ruiz²; Eleazar Lara Padilla3; Rosalba Garduño Zarazúa ${ }^{1}$; Antonio Franco Vadillo3; José de Jesús Peralta Romero ${ }^{4}$, José Bruno Mendoza Ramírez²; Adrian Hugh Heald ${ }^{5}$; Javier Mancilla Ramírez ${ }^{1}$,

1. Dirección General de Calidad y Educación en Salud. Secretaria de Salud. México

2. Centro Nacional de Cálculo del Instituto Politécnico Nacional

3. Escuela Superior de Medicina del Instituto Politécnico Nacional

4. Unidad de Investigación Médica en Bioquímica. Unidad Médica de Alta Especialidad “Dr. Bernardo Sepúlveda" del Centro Médico Nacional Siglo XXI, IMSS, Ciudad de México.

5. Salford Royal Hospitals NHS Trust, Department of Endocrinology and Diabetes;

6. The University of Manchester, School of Medicine and Manchester Academic Health Sciences Centre

\section{Contributions}

Gabriela Yanet Cortés Moreno and Javier Mancilla Ramírez conceived the study and recorded, Miguel J. Torres Ruiz analyzed and interpreted the data. Gabriela Y Cortés, and Adrian Heald contributed in writing the manuscript. Eleazar Lara Padilla and José de Jesus Peralta assisted with methodology. Bruno Mendoza Ramirez made the database together with Antonio Franco. Javier Mancilla Ramírez confirmed coding. All authors read and approved the final manuscript.

\section{Acknowledgements}

To José Edilberto Becerra Sanchez, Ernesto López Caballero and Patricia Rodriguez Escobar for their participation in the study.

\section{References}

1. Informe Técnico Diario COVID-19 MÉXICO. Gobierno de México. Secretaria de Salud, December 28, 2020.https://www.gob.mx/cms/uploads/attachment/file/602724/Comunicado_Tecnico_Diario_COVID19_2020.12.28.pdf.

2. Liu X, Zhuang W, Quan X, Zhou Y, Qin H, Zou C, et al. An especial transition phase of hospitals: the adaptation of hospital operations to the development of COVID-19 and policy adjustments. Environ Health Prev Med. 2020;25(1):55.

3. Benítez MA, Velasco C, Sequeira AR, Henríquez J, Menezes FM, Paolucci F. Responses to COVID-19 in five Latin American countries. Health Policy Technol. 2020:449-.

4. Checklist for the Management of Human Resources for Health. in Response to COVID-19, Washington, D.C. Pan American Health Organization, April 15, 2020. https://iris.paho.org/handle/10665.2/52122? show=full. 
5. Valdez-García JE, López CMV, Jiménez MMÁ, et al. Me preparo para ayudar: respuesta de escuelas de medicina y ciencias de la salud ante COVID-19. Inv Ed Med. 2020;9(35):85-95.

6. Reyes PA, Delong RC. Algunos dilemas éticos en la práctica médica. Arch de cardiología de México. 2010;80(4):338-42.

7. Gallagher TH, Schleyer AM. "We Signed Up for This!" - Student and Trainee Responses to the Covid-19 Pandemic. N Engl J Med. 2020;382(25):e96.

8. Everitt BS, Landau S, Leese M, Stahl D. (2011) Cluster analysis, 5th edition, Wiley, ISBN: 978-0-47097844-3.

9. Mohammad SM, Turney PD. NRC emotion lexicon. Ottawa: National Research Council; 2013. pp. 1234.

10. Lineamiento de reconvención hospitalaria. Gobierno de México. Secretaria de Salud, April 22. 2020 https://coronavirus.gob.mx/wp-content/uploads/2020/07/Lineamientos-ReconversionHospitalaria_05042020_2.pdf.

11. Preparación y Respuesta frente a casos de SARS-CoV2-2019 para la atención primaria a la salud. Gobierno de México. Secretaria de Salud, April 22, 2020. https://coronavirus.gob.mx/wpcontent/uploads/2020/04/Preparacion_respuesta_casos_SARS-CoV2_atencion_primaria.pdf.

12. Lineamientos de implementación de Centros de Atención. Temporal COVID-19 (CAT-COVID19) y Hospitales Móviles (EMT). Gobierno de México. Secretaria de Salud. April 9, 2020. https://coronavirus.gob.mx/wpcontent/uploads/2020/04/Lineamientos_Centros_Atencion_Temporal.pdf.

13. Comunicado para personal en formación en áreas de la salud. FASE 3. Gobierno de México. Secretaria de Salud, April 22, 2020. http://www.calidad.salud.gob.mx/site/docs/Comunicado_personal_en_formacion_F3.pdf.

14. Nuñez CJ, Reussi R, Garcia DM, Falasco S. COVID-19 y la educación médica, una mirada hacia el futuro. Foro Iberoamericano de Educación Médica (FIAEM). Educ Med. 2020;21(4):251-8.

15. Zegarra A, Chino B, Ames R. Knowledge, perception and attitudes in Regard to COVID19. Pandemic in Peruvian Population. 2020. doi:10.31234/osf.io/kr9ya.

16. Zhong BL, Luo W, Li HM, Zhang QQ, Liu XG, Li WT, et al. Knowledge, attitudes, and practices towards COVID-19 among Chinese residents during the rapid rise period of the COVID-19 outbreak: a quick online cross-sectional survey. Int J Biol Sci. 2020;16(10):1745-52.

17. Talevi D, Socci V, Carai M, Carnaghi G, Faleri S, Trebbi E, et al. Mental health outcomes of the CoViD-19 pandemic. Riv Psichiatr. 2020;55(3):137-44.

18. Reger MA, Piccirillo ML, Buchman-Schmitt JM. COVID-19, Mental Health, and Suicide Risk Among Health Care Workers: Looking Beyond the Crisis. The Journal of clinical psychiatry. 2020 ago 4;81(5). https://doi.org/10.4088/JCP.20com13381.

19. El-Hage W, Hingray C, Lemogne C, Yrondi A, Brunault P, Bienvenu T, et al. Les professionnels de santé face à la pandémie de la maladie à coronavirus (COVID-19): quels risques pour leur santé mentale ? L'Encéphale. 2020;46(3):73-80. 
20. Johnson MC, Saletti-Cuesta L, Tumas N. Emociones, preocupaciones y reflexiones frente a la pandemia del COVID-19 en Argentina. Ciência \& Saúde Coletiva. 2020;25:2447-56.

21. Ortiz Z, Antonietti L, Capriati A, Ramos S, Romero M, Mariani J, et al. Preocupaciones y demandas frente a covid-19. Encuesta al personal de salud. Med (Buenos aires). 2020;80(3):16-24.

22. Li L, Xv Q, Yan J. COVID-19: the need for continuous medical education and training. Lancet Respir Med. 2020;8(4):e23.

\section{Figures}

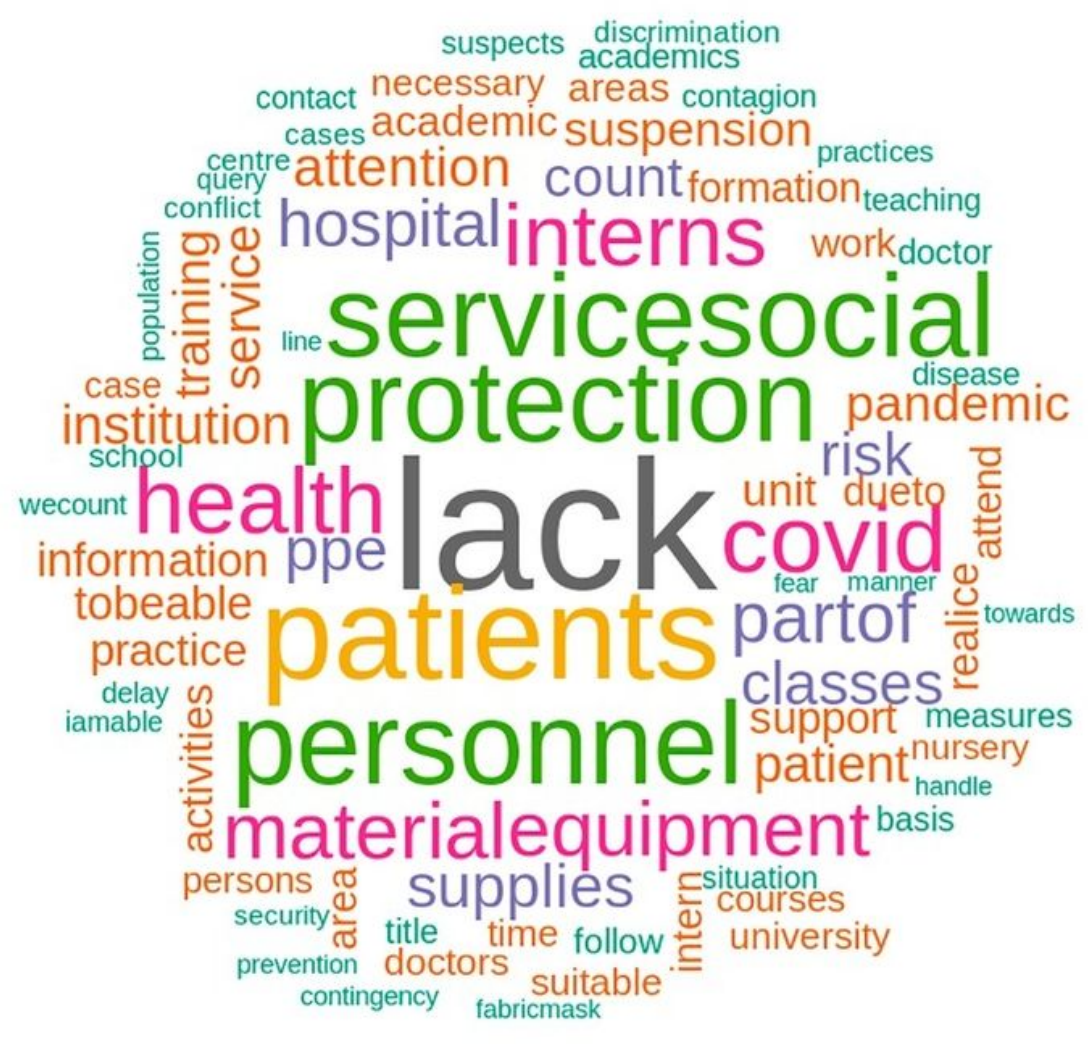

Figure 1

Word cloud applying data mining functions on the corpus generated by the answers 


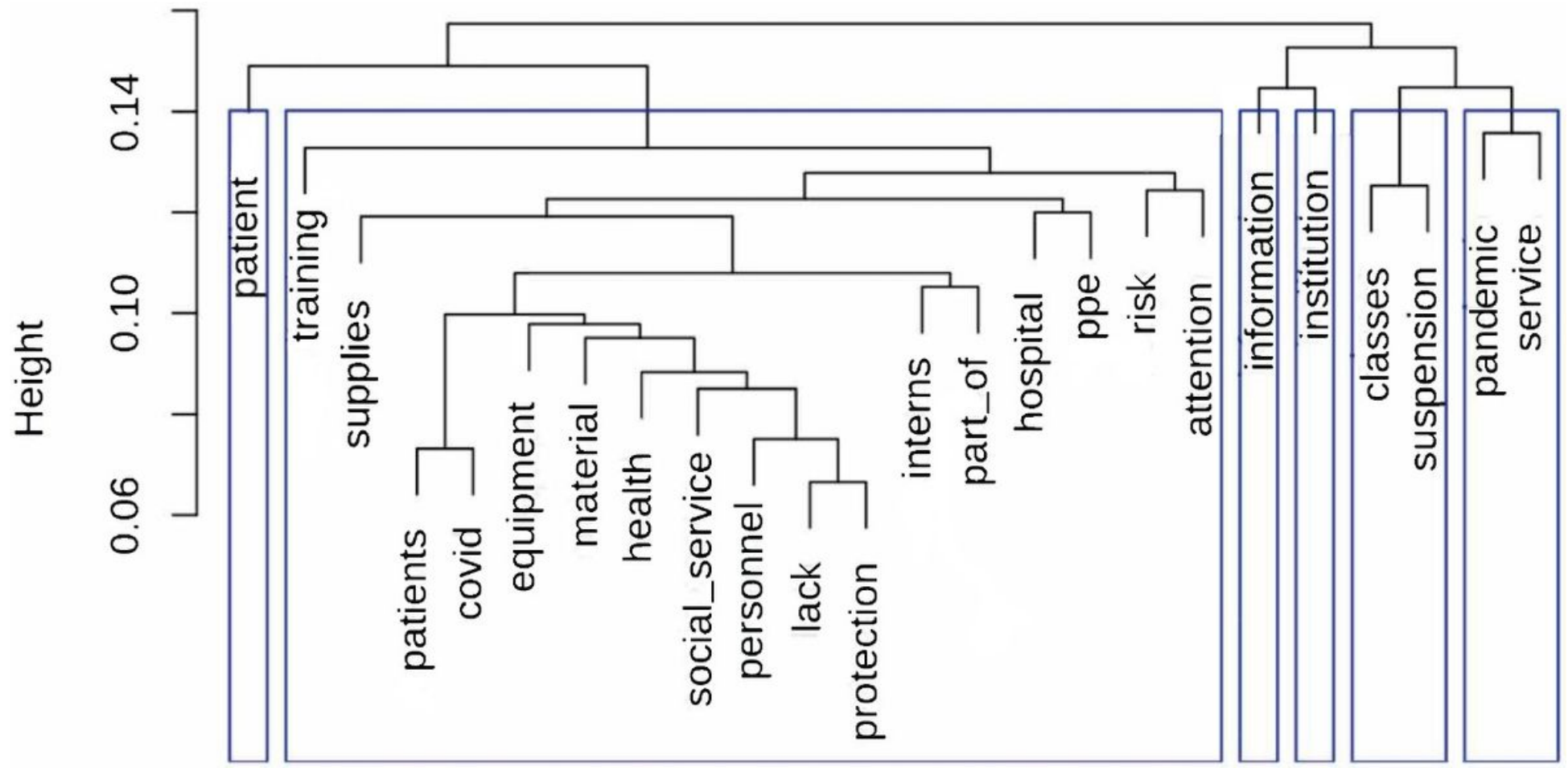

Figure 2

Dendrogram of the semantic relationship between the terms 